\section{Nipple and Areolar Eczema in the Breastfeeding Woman}

\author{
Benjamin Barankin, and M. Shirley Gross ${ }^{1,2}$
}

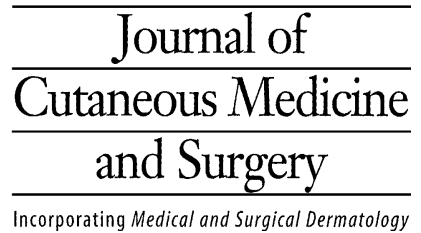

DOI: $10.1007 / \mathrm{s} 10227-004-0116-6$

J Cutan Med Surg 2004; 126-130

\title{
Abstract
}

Eczema of the nipple and areola can occasionally develop in the breastfeeding patient and is associated with sore, burning, and painful areolae and nipples. Management includes elimination of any precipitating allergens and irritants and the judicious use of appropriate topical corticosteroid preparations. Patients must also be offered effective pain control and support. The proper diagnosis and management of eczema of the nipple and areola in breastfeeding patients will prevent premature and iatrogenic weaning.

\section{Sommaire}

L'eczéma du mamelon et de L'aréole peut parfois apparaître chez des patientes qui allaitent et en conjonction avec des douleurs et des brûlures. La gestion de L'eczéma comprend L'élimination de tout allergène et irritant à effet indésirable ainsi que L'usage judicieux de préparations corticoïdes appropriées. Les patientes doivent également recevoir un L'appui adéquat et des moyens efficaces de maîtriser la douleur. Le diagnostic et la gestion appropriés de L'eczéma du mamelon et de L'aréole durant la période d'allaitement contribueront à éviter le sevrage prématuré et iatrogène.

$\mathrm{B}$ reastfeeding women may develop various illnesses and pathologies. Fortunately, the vast majority are curable. Some problems, such as nipple fissures, are unique to breastfeeding women. Others, such as candidiasis and eczema, are seen in the general population but may have an atypical presentation in the breastfeeding patient.

The incidence of eczema of the nipple and areola is unknown and the literature is limited to case reports. In the past 22 months (since January 2002), we have seen 1016 patients and 17 had eczema (1.7\%). Fortunately, eczema is well studied in non-nursing patients and such information is presumably applicable to breastfeeding patients as well.

\section{Clinical Presentation}

Eczema of the areola and nipple most commonly affects the areola and occasionally extends to the breast. ${ }^{1}$ It tends to spare the area of the areola immediately adjacent to the base of the nipple. The nipple is much less frequently affected. Eczema of the areola can present acutely as an erythematous eruption with vesicles, crusting, and erosions $^{2}$ (Fig. 1). It can also occur in a subacute and chronic presentation as a dry, erythematous, lichenified,

${ }^{1}$ University of Alberta, Edmunton, Alberta, Canada Online publication: 3 May 2004

Correspondence to: M. Shirley Gross, Misericordia Child Health Clinic, Unit 3 West, 16940-87 Ave., Edmonton, Alberta, Canada T5R 4H5. E-mail: sgross@cha.ab.ca and scaling dermatitis ${ }^{3}$ (Fig. 2). Patients describe the lesions as pruritic, painful, or burning ${ }^{1,3}$

\section{Etiology}

The nipple and areola are covered by keratinized, stratified, squamous epithelium. This is the same type of epithelium that is found elsewhere on the trunk, head, and limbs and that can present with eczema.

Eczema is a term used to describe the clinical presentation of several types of dermatitis. Dermatitis of the body has three main types: endogenous atopic eczema, irritant contact dermatitis, and allergic contact dermatitis. Less common types include nummular eczema, nutritional deficiency eczema, hormone-induced eczema, and neurodermatitis.

\section{Endogenous Atopic Eczema}

Patients with endogenous atopic eczema are more prone to nipple eczema, a minor criterion in Hanifin and Rajka's diagnostic criteria for atopic dermatitis. ${ }^{4}$ Chronic endogenous atopic eczema appears dry, lichenified, and diffuse, with an underlying background of erythema, while acute eruptions occur with blistering, oozing lesions and swelling in the affected areas. ${ }^{5}$ Our experience shows that approximately half of breastfeeding women who developed nipple and areola eczema had a prior history of eczema and the other half developed it as a contact dermatitis following introduction of solids to the infant's diet. 
FIGURE 1 Acute or "wet" eczema showing bright erythema and erosions.

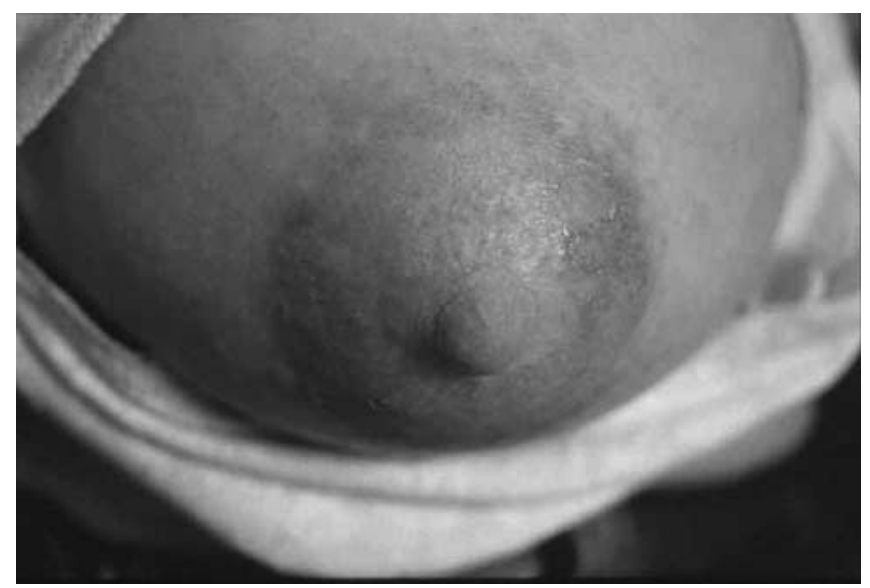

FIGURE 2 Subacute or "dry" eczema showing a dull erythema and lichenification.

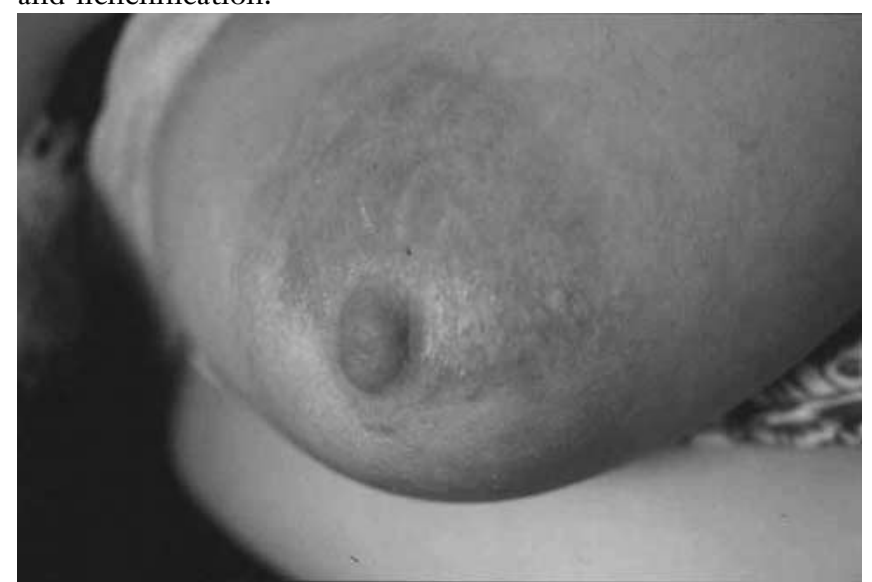

\section{Irritant Contact Dermatitis}

This type of dermatitis is caused by irritation of the skin. Reported agents include water, soaps, detergents, and fragrances. ${ }^{5-7}$ Eczema of the areola and nipple may be caused by washing the nipples with soap or by applying ointments that contain irritants. Physicians must consider any topical agents, any washing detergent, and even chlorine clothing bleach as possible irritants. ${ }^{8,9}$

\section{Allergic Contact Dermatitis}

This is a delayed hypersensitivity reaction to an allergen in a topical agent used on the nipples. Offending agents can include chamomile, ${ }^{10,11}$ vitamins $\mathrm{A}$ and $\mathrm{E},{ }^{12}$ aloe vera, ${ }^{13}$ and perfumes. ${ }^{14}$ Lanolin is a purified anhydrous waxy substance obtained from the wool of sheep that can cause sensitization. This is more common when lanolin is used as a topical therapeutic agent or on atopic patients as opposed to it being used in cosmetic preparations in nonatopic patients. ${ }^{15,16}$ Dermatitis from preservatives used in some mycostatin formulations has also been reported. ${ }^{17-19}$
FIGURE 3 Nipple candidiasis showing erythema, fine fissuring at the base of the nipple, and involvement of the areola immediately adjacent to the nipple.

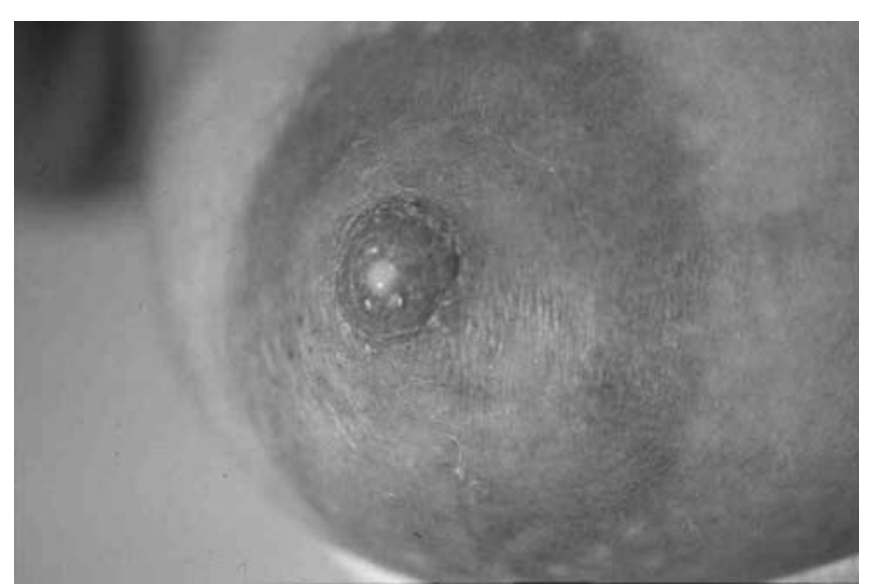

\section{Differential Diagnosis}

\section{Bacterial Infection of the Breast}

Bacterial infections of the skin can take the form of impetigo and cellulitis, as well as mastitis. Clinically, there is a unilateral pain, tenderness, and erythema. Antibiotic therapy targeted at Staphylococcus aureus and Group A Streptococcus (GAS) is required. If an abscess develops in mastitis,(this is best accomplished through needle aspiration ussing appropriate analgesia) incision and drainage is necessary.

\section{Candidal Infection of the Breast}

Mammary candidiasis can sting, burn, or itch. Physical findings of the central areola can include a normal examination, slight to extreme erythema, shininess, lichenification, or eczematous changes. These changes are usually limited to the area of the areola in contact with the baby's mouth. Unlike dermatitis, mammary candidiasis does not spare the area of the areola immediately adjacent to the nipple. Indeed, fine hair-line cracks at the base of the nipple may also develop in severe cases. ${ }^{20,21}$ As with eczema, symptoms can occur suddenly after a mother has had pain-free nursing for some time..$^{21,22}$ Mammary candidiasis is associated with oral thrush in the nurseling, ${ }^{23}$ antibiotic use, ${ }^{24}$ nipple cracks and damage, ${ }^{25}$ and a prior history of vaginal candidiasis, ${ }^{25}$ although only a small number of studies are available and few of these included candida laboratory confirmation. ${ }^{25}$

\section{Mammary Paget's Disease}

Paget's disease may present as a unilateral and chronic eczematous-appearing rash of the areaola and nipple. This is a slow-growing intraductal carcinoma that infiltrates the nipple and most often occurs in postmenopausal women (two-thirds of cases), but it has been reported in a younger population. ${ }^{21,26}$ It presents as a slowly advancing nipple eczema that does not respond to 
medical therapy. One must be suspicious of Paget's disease if "eczema" is unilateral or persists for more than 3 weeks. ${ }^{27}$ Treatment options are surgery, radiotherapy, and/or chemotherapy. It represents $1 \%-4 \%$ of all breast cancers and very rarely affects males. ${ }^{28}$ The intraductal carcinoma is palpable in $31 \%-62 \%$ of affected patients. $^{22,27}$ This would be a rare event in the breastfeeding mother and thus far has not been reported in the literature.

\section{Management}

\section{Prevention}

Any maternal history of atopy, eczema, allergic and irritant contact dermatitis should be identified. Any possible precipitating allergens and irritants should be discontinued. Nipple eczema may also develop when the infant begins solid foods that secondarily act as allergens on the mother's nipples. In this situation, it may be helpful to encourage mothers to start complementary foods at six months and not before. While the six-month start date for complementary foods is the current recommendation of most groups and organizations, ${ }^{29,30}$ existing practices favor earlier start dates.

Moisturization is an important part of general eczema management. Interestingly, our experience shows that breastfeeding mothers either have eczema or they have normal skin. Xerosis of the nipple-areola complex is quite rare in this population.

\section{Treatment}

Topical corticosteroids are the mainstay of treatment for most episodes of eczema. The duration of use and steroid strength should be determined by the patient's presentation and response. Moderately potent topical steroids are effective but should be reserved for severe or recalcitrant cases and should be used for no longer than 3-5 days at a time. Low-potency topical steroids are useful both in mild cases or for maintenance after use of a moderately potent steroid for another 1-2 weeks of therapy. ${ }^{31}$ Ointments are preferable to creams as they are more easily absorbed. The areolar skin is very thin and topical corticosteroids are well absorbed and very effective. As topical corticosteroids are not without side effects, including skin atrophy, telangiectasia, striae, and contact dermatitis, ${ }^{32}$ their use should be closely supervised and, where possible, minimized.

Topical corticosteroids should be applied to the affected areas after the infant has fed. These products should not be ingested by nurselings since adenocorticoid and mineralocorticoid changes can ensue. ${ }^{33}$ The mother should receive clear instructions to wipe the cream off the nipple and areola. This is most easily accomplished by the mother expressing a small amount of milk from the breast and using this to wash off the steroid cream. This should be done twice before any feeds to ensure thorough cleansing. Milk is preferable to water as it is immediately available and the presence of a small amount of milk fat might avoid some of the drying and irritating effects of water.

The recent availability and efficacy of topical tacrolimus and pimecrolimus are beneficial additions to the dermatologist's armamentarium, although their use in nipple and areola eczema and their effects on the nurseling have yet to be specifically studied. ${ }^{34,35}$

Staphylococcus aureus is a common skin pathogen. It also colonizes the nipple ${ }^{36}$ and is strongly associated with nipple fissures. ${ }^{37}$ Furthermore, many patients with atopic dermatitis have colonization by Staphylococcus aureus. ${ }^{38}$ As with fissures, the loss of skin integrity caused by nipple and areolar eczema can also increase the risk of local secondary bacterial infection. Furthermore, infected fissures, by facilitating ascending infections, increase the risk of mastitis or breast abscess. ${ }^{39}$ Secondary bacterial infections of areolar eczema must be assumed to have the same risks and be treated appropriately.

The treatment of infected eczema with a topical antibiotic such as mupirocin has been shown to reduce the bacterial count and clinical severity. ${ }^{40}$ However, a study of nipple wounds found that systemic penicillinase-resistant oral antibiotic therapy for 10-days duration was more effective in both eradicating infection and preventing reoccurrence compared with topical therapy. ${ }^{39}$ There is also evidence of increasing microbial resistance to some topical preparations such as mupirocin. ${ }^{38}$ Other preparations such as polysporin and fusidic acid are similarly effective as mupirocin.

Eczema of the areola and nipple can also be very painful. This is best managed with oral analgesia such as acetaminophen or codeine, both of which are compatible with nursing, ${ }^{41}$ are timely and effective treatment, and provide ongoing support. If a patient is experiencing too much pain with nursing, she can be offered a silicone nipple shield or, failing this, she can pump or manually express her milk. Pumping and manual expression should be avoided if at all possible as they are both very time consuming and not effective at removing milk for some mothers. Nurselings should be returned to breast as soon as the mother feels able to nurse as continued use of any artificial feeding device might compromise breastfeeding.

If eczema has developed around the time of solid introduction, the mother should be instructed to rinse the nipple and areola with her own expressed milk or water and gently pat dry after feeds. She should be asked to identify and eliminate any possible infant foods that might have contributed to the onset of eczema while ensuring this will not compromise the baby's nutrition.

Breastfeeding resources, such as breastfeeding clinics and lactation consultants, exist in most communities. They are able to provide patients with assistance regarding manual expression of milk and breastfeeding devices such as pumps and nipple shields. They can provide guidance and education about the risks and benefits of breastfeeding in these and other situations. 
Furthermore, physicians with a special interest in breastfeeding are able to offer expert advice and assistance should it be required.

\section{Diagnostic Procedures}

If there is scale and an active edge to a rash or maceration around the nipple-areola complex, scraping and performing a $\mathrm{KOH}$ as well as fungal culture is beneficial for an accurate diagnosis. In suspected bacterial infections, a swab for bacterial culture may also be useful for speciation and sensitivities. In the rare instance that Paget's disease is a concern, a skin biopsy is required.

\section{Side Effects/Problem}

As the benefits of breastfeeding are marked for both mother and child, even with medication use, it is rare that the risks of nursing will outweigh the benefits. ${ }^{42}$ There is only one reference of infant exposure to topical steroids absorbed from a mother's nipples that resulted in suppression of the pituitary-adrenal axis; in this case, the mother had used a fluorinated corticosteroid nipple cream for two months. ${ }^{42}$ Nevertheless, this case does illustrate the importance of minimizing exposure to the infant. There is extensive evidence of the side effects of oral corticosteroids and thus mothers should be strongly encouraged to cleanse the areola and nipple prior to nursing, as described above.

\section{Breastfeeding}

Breastfeeding is the ideal milk for infants. The benefits include a decreased risk of infectious disease, insulindependent diabetes mellitus, Crohn's disease, ulcerative colitis, and childhood cancers. There is also evidence suggesting enhancement of cognitive function. Maternal benefits include decreased blood loss postpartum, delay in return to fertility, deceased risk of breast and ovarian cancer, and improved bone remineralization postpartum. $^{21}$

For the family with a history of atopic disease, there is evidence for the protective function of exclusive breastfeeding during the first six months after birth in preventing childhood atopic dermatitis. ${ }^{34,43}$ This benefit may also extend into adolescence. ${ }^{44}$ In particular, patients with a positive family history of atopy most strongly benefit from the protective effects of breastfeeding. ${ }^{42-45}$ Many of the studies that have assessed the ability of breastfeeding to delay or prevent allergic disease have methodologic problems. However, taken as a whole, these studies suggest that exclusive breastfeeding has a protective effect in high-risk children. ${ }^{46}$ This beneficial effect is further enhanced if mothers of high-risk children avoid common allergenic foods during lactation. ${ }^{42-44}$

Because of the numerous and marked health benefits for mother and infant, breastfeeding is recommended for two and more years. ${ }^{42}$
Infants who are at high risk of developing allergy and whose mothers elect to wean may benefit from hypoallergenic formula. This may result in fewer atopic manifestations compared with the use of cow's milk-based formula or soy formula. ${ }^{42,44,47,48}$

An understanding of nipple and areolar eczema and of the importance of promoting and preserving breastfeeding will allow dermatologists to provide effective care for both mothers and babies.

\section{References}

1. Amir L. Eczema of the nipple and breast: a case report. J Hum Lact 1993; 9:173-175.

2. Rago JL. Weeping areolar eczema. J Hum Lact 1988; 4:166167.

3. Brackett VH. Eczema of the nipple/areola area. J Hum Lact 1988; 4:167-169.

4. Hanifin JM, Rajka G. Diagnostic features of atopic dermatitis. Acta Derm Venereol Suppl (Stockh) 1980; 92:44-47.

5. Odom RB, James WD, Berger TG. Atopic dermatitis, eczema, and noninfectious immunodeficiency disorders. Andrews' diseases of the skin. Toronto: W.B. Saunders, 2000, pp 76-84.

6. Warren R, Ertel KD, Bartolo RG, et al. The influence of hard water (calcium) and surfactants on irritant contact dermatitis. Contact Dermatitis 1996; 35:337-343.

7. Frosch PJ, Pilz B, Andersen KE, et al. Patch testing with fragrances: results of a multicenter study of the European Environmental and Contact Dermatitis Research Group with 48 frequently used constituents of perfumes. Contact Dermatitis 1995; 33:333-342.

8. Nettis E, Colanardi MC, Soccio AL, et al. Occupational irritant and allergic contact dermatitis among healthcare workers. Contact Dermatitis 2002; 46:101-107.

9. Tupker RA, Bunte EE, Fidler V, et al. Irritancy ranking of anionic detergents using one-time occlusive, repeated occlusive and repeated open tests. Contact Dermatitis 1999; 40:316-322.

10. Flyvholm MA. Contact allergens in registered cleaning agents for industrial and household use. Br J Ind Med 1993; 50:10431050.

11. Giordano-Labadie F, Schwarze HP, et al. Allergic contact dermatitis from camomile used in phytotherapy. Contact Dermatitis 2000; 42:247.

12. Bossuyt L, Dooms-Goossens A. Contact sensitivity to nettles and camomile in 'alternative' remedies. Contact Dermatitis 1994; 31:131-132.

13. Bazzano C, Angeles S de, Kleist G, et al. Allergic contact dermatitis from topical vitamins A and E. Contact Dermatitis 1996; 35:261262.

14. Morrow DM, Rapaport MJ, Strick RA. Hypersensitivity to aloe. Arch Dermatol 1980; 116:1064-1065.

15. Buckley DA, Wakelin SH, Seed PT, et al. The frequency of fragrance allergy in a patch-test population over a 17 -year period. $\mathrm{Br} \mathrm{J}$ Dermatol 2000; 142:279-283.

16. Wolf R. The lanolin paradox. Dermatology 1996; 192:198-202.

17. Wilson CL, Cameron J, Powell SM, et al. High incidence of contact dermatitis in leg-ulcer patients-implications for management. Clin Exp Dermatol 1991; 16:250-253.

18. Tait P. Nipple pain in breastfeeding women: causes, treatment, and prevention strategies. J Midwifery Womens Health 2000; 45:212215.

19. Cooper SM, Shaw S. Contact allergy to nystatin: an unusual allergen. Contact Dermatitis 1999; 41:120.

20. Fisher AA. Unnecessary addition of ethylenediamine hydrochloride to "generic" nystatin creams. J Am Acad Dermatol 1989; 20:129_ 130 .

21. Heinig MJ, Francis J, Pappagianis D. Mammary candidosis in lactating women. J Hum Lact 1999; 15:281-288.

22. Amir LH, Garland SM, Dennerstein L, et al. Candida albicans: is it associated with nipple pain in lactating women? Gynecol Obstet Invest 1996; 41:30-34.

23. Chaudary MA, Millis RR, Lane EB, et al. Paget's disease of the nipple: a ten year review including clinical, pathological, and im- 
munohistochemical findings. Breast Cancer Res Treat 1986; 8:139146.

24. Amir LH. Candida and the lactating breast: predisposing factors. J Hum Lact 1991; 7:177-181.

25. Tanguay KE, McBean MR, Jain E. Nipple candidiasis among breastfeeding mothers. Case-control study of predisposing factors. Can Fam Physician 1994; 40:1407-1413.

26. Dixon AR, Galea MH, Ellis IO, et al. Paget's disease of the nipple. Br J Surg 1991; 78:722-723.

27. Jamali FR, Ricci A Jr, Deckers PJ. Paget's disease of the nippleareola complex. Surg Clin North Am 1996; 76:365-381.

28. Fitzpatrick T, Johnson R, et al. Color atlas and synopsis of clinical dermatology.3McGraw Hill, New York 1997.

29. Paone JF, Baker RR. Pathogenesis and treatment of Paget's disease of the breast. Cancer 1981; 48:825-829.

30. World Health Organization. WHA54/inf.doc./4 Global strategy for infant and young child feeding: the optimal duration of exclusive breastfeeding.

31. WorkGroup on Breastfeeding. AmericanAcademy of Pediatrics.Breastfeeding and the use of human milk. Pediatrics 1997; 1006:1035-1039.

32. Reeves J, Maibach H. Clinical dermatology illustrated: a regional approach.2MacLennan \& Petty, Sydney 1992, pp 174-175362-363; $402-404$.

33. Odom RB, James WD, Berger TG. Contact dermatitis and drug eruptions: adverse reactions to corticosteroids. Andrews' diseases of the skin. Toronto: W.B. Saunders, 2000, pp 142-145.

34. Stefano P De, Bongo IG, Borgna-Pignatti C, et al. Factitious hypertension with mineralocorticoid excess in an infant. Helv Paediatr Acta 1983; 38:185-189.

35. Hanifin JM, Ling MR, Langley R, et al. Tacrolimus ointment for the treatment of atopic dermatitis in adult patients: part I, efficacy. J Am Acad Dermatol 2001; 44:S28-S38.

36. Eichenfield LF, Lucky AW, Boguniewicz M, et al. Safety and efficacy of pimecrolimus (ASM 981) cream 1\% in the treatment of mild and moderate atopic dermatitis in children and adolescents. J Am Acad Dermatol 2002; 46:495-504.
37. Sytnik SI. [Staphylococci in skin microbiocenosis of the breasts in nursing women]. Zh Mikrobiol Epidemiol Immunobiol 1988; $23-$ 27.

38. Livingstone V, Stringer LJ. The treatment of Staphyloccocus aureus infected sore nipples: a randomized comparative study. J Hum Lact 1999; 15:241-246.

39. Lever R, Hadley K, Downey D, et al. Staphylococcal colonization in atopic dermatitis and the effect of topical mupirocin therapy. Br J Dermatol 1988; 119:189-198.

40. Fetherson C. Management of lactation mastitis in a Western Australian cohort. Breastfeeding Rev 1997; 5:13-19.

41. Deshpande LM, Fix AM, Pfaller MA, et al. Emerging elevated mupirocin resistance rates among Staphylococcal isolates in the SENTRY Antimicrobial Surveillance Program (2000): correlations of results from disk diffusion, Etest and reference dilution methods. Diagn Microbiol Infect Dis 2002; 42:283290.

42. American Academy of Pediatrics, Committee on Nutrition. Hypoallergenic Infant formulas. Pediatrics 2000 2000; 1062:346349.

43. Gdalevich M, Mimouni D, David M, et al. Breast-feeding and the onset of atopic dermatitis in childhood: a systematic review arid and meta-analysis of prospective studies. J Am Acad Dermatol 2001; 45:520-527.

44. Chandra RK, Puri S, Hamed A. Influence of maternal diet during lactation and use of formula feeds on development of atopic eczema in high risk infants. BMJ 1989; 299:228-230.

45. Saarinen UM, Kajosaari M. Breastfeeding as prophylaxis against atopic disease: prospective follow-up study until 17 years old. Lancet 1995; 346:1065-1069.

46. Effendy I, Maibach HI. Detergent and skin irritation. Clin Dermatol 1996; 14:15-21.

47. World Health Assembly. WHA 47.5. Agenda Item 19, Infant and Young Child Nutrition, 1994.

48. Chandra RK, Hamed A. Cumulative incidence of atopic disorders in high risk infants fed whey hydrolysate, soy, and conventional cow milk formulas. Ann Allergy 1991; 67:129-132. 